\title{
Spermatozoa retrieval for cryopreservation after death
}

\author{
Fernando Lorenzini ${ }^{1}$, Eduardo Zanchet ${ }^{1}$, Gustavo M. Paul ${ }^{1}$, Ricardo T. Beck ${ }^{1}$, Mariana S. Lorenzini ${ }^{1}$, \\ Elisângela Böhme ${ }^{1}$
}

${ }^{1}$ Centro de Reprodução Humana Curitiba, PR, Brasil

\section{ABSTRACT}

Objectives: To describe the retrieval spermatozoa technique for cryopreservation after death, including the proximal part of vas deferens.

Material and Methods: A 28-years old man, with previous history of infertility, who had died 12 hours before, was submitted to spermatozoa retrieval for cryopreservation, with surgical bilateral resection in bloc of the proximal part of vas deferens, testicle and epididymis. At the laboratory, by milking the epididymis and vas deferens, the extracted fluid was collected; also, three samples of each testicle parenchyma were also harvested.

Results: The fluid from the vas deferens showed spermatozoa, mostly with in situ motility. Testicular fragments also presented spermatozoa, mostly with small tail movements or immobile.

Conclusion: The inclusion of the proximal part of vas deferens during spermatozoa retrieval after death must be performed, since it contains high concentration of spermatozoa, and even in the presence of previous infertility, as was with this patient, it is possible to retrieve spermatozoa.

\section{ARTICLE INFO}

\section{Keywords:}

Cryopreservation; Spermatozoa;

Vas Deferens; Testis

Int Braz J Urol. 2018; 44: 188-91

Submitted for publication:

April 20, 2017

Accepted after revision:

June 04, 2017

Published as Ahead of Print:

August 11, 2017

\section{INTRODUCTION}

Cryopreservation of spermatozoa after death allows parenthood using assisted reproductive technologies.

The success of spermatozoa retrieval after death depends on the time from death to cryopreservation, on the quality of previous spermatogenesis and the harvested anatomic structures. Post-mortem viability is inversely proportional to the time from death to sperm retrieval (1).

The first report on sperm retrieval after death was published in 1980. It describes the sperm retrieval of a 30-years old man with encephalic death due to trauma (2). In 1993, it was reported the birth of the first child using cryopreserved spermatozoa collected after death (3).
The objective of the present paper is to describe the employed technique for posthumous sperm retrieval and cryopreservation including the proximal part of the vas deferens during surgical collection.

\section{MATERIALS AND METHODS}

A 28-years old white man, that had died 12 hours before o was submitted to sperm retrieval for cryopreservation requested by his wife.

Before the procedure, a written consent was signed.

Surgical technique of sperm retrieval used the following sterile surgical steps: patient in dorsal decubitus, antisepsis of genital skin, sterile drapes protecting the surgical field, $4 \mathrm{~cm}$ longitudinal 
median incision of scrotal pouch, opening of bilateral vaginal layer, in bloc bilateral resection of proximal $5 \mathrm{~cm}$ of vas deferens, testicle and epididymis, closure of incision with continuous suture in two layers. Each of the two tissue resected parts was separately involved in sterile drapes, stored in a plastic sterile bag of 15 liters and both were kept in a refrigerated box for biological transport.

For cryopreservation of biological tissue, at the reproduction laboratory, under sterile conditions, it was performed milking of epididymis and vas deferens, and the collected fluid was added to $3 \mathrm{~mL}$ of culture media in a test tube (single step medium, Irvine Scientific ${ }^{\circledR}$, Santa Ana, EUA). Also, three samples of $3 \times 3 \times 3 \mathrm{~mm}$ of testicular parenchyma of each testicle (superior, medium and inferior anterior region) were harvested and immersed in a vial with the same culture media. The fluid of the vas deferens ends and the testicle fragments were cryopreserved in liquid nitrogen, using the fast freezing technique (4), with the aid of a cryoprotector media (test-yolk buffer com glicerol, Irvine Scientific ${ }^{\circledR}$, Santa Ana, EUA).

For microscopic analysis, three other samples of the fluid of both vas deferens were collected (20 microliters each), along with three other small resected samples of testicular parenchyma (1x1x1mm each), from the superior, medium and inferior region.

\section{RESULTS}

The proximal part of vas deferens, testicles and epididymis showed macroscopic normal characteristics. Microscopic evaluation of the collected fluid from vas deferens showed the presence of rare spermatozoa in each optic field (200X), mostly with in situ motility. Testicular fragments also presented spermatozoa, mostly with small tail movements or immobile.

\section{DISCUSSION}

Sperm cryopreservation and assisted reproductive technologies allow posthumous parenthood (5). Family members may express this wish and seek help from trained professionals for post mortem cryopreservation of retrieved sperm, as soon as possible, after death. Usually there is no such team on call for this procedures in these rare occasions, but they must follow some aligned steps: a) legal aspects (authorization and legal consent); b) choice of biological material to be harvested with the highest probability to contain viable sperm in adequate quantity; c) packaging, transportation and processing of the material at the reproduction laboratory.

Post-mortem gamete cryopreservation legislation in several countries is conflictive or nonexistent. In many occasions, local laws, institutional guidelines and judicial decisions are used (6). World legislation is not consensual regarding legality of the procedure. In France, Germany, Spain, Canada and Sweden the procedure is forbidden, even with previous consent of the deceased (1). In United Kingdom the deceased donor must have previously consented the use of his genetic material after death (7). In Israel, legislation is more liberal: the widow may request the retrieval and use of genetic material (8). In the United States and Australia there are no specific laws; it is recommended that medical societies determine the guidelines for the procedure. Usually these societies recommends a previous consent of the deceased and a minimum interval of six to 12 months between the retrieval and the use in assisted reproduction. These same societies do not recommend the material collection in situations of familiar dispute (9). A question form of semen donors of semen banks in the US showed that $85.9 \%$ of donors would agree to the use of their genetic material if they died and among infertile patients 83.8\% agreed (6). In Brazil, the Federal Board of Medicine in 1998 recommended that spouses when alive signed a written consent to inform their wish on the destiny of embryos and/or any cryopreserved reproductive material in case of divorce, severe illness of death. Federal justice board defined that to presume paternity, offspring may be obtained by the widow with express authorization of husband when alive, to use his genetic material (10). In the present case, it was requested authorization and written consent, but, almost one year after cryopreservation, the widow asked for discard of all material, signing a written consent form. 
Regarding anatomic sites or tissues that must be harvest for sperm retrieval after death, there is no standardization in literature. Usually, it is recommended to harvest testicles and/or epididymis, including the higher possible amount of biological tissue (11). Techniques that use needle percutaneous collection of testicles, epididymis and vas deferens are not ideal, in view of the small quantity of sperm retrieved, although vas deferens needle puncture may present higher success. Electroejaculation may be an alternative for patients with brain death maintained with mechanic ventilation $(12,13)$. In the present technique, it was surgically collected the testicles, epididymis, proximal parts of vas deferens, that were harvested in bloc to perform the proximal to distal milking maneuver (from the epididymis to the vas deferens) to collect the highest quantity of fluid. The vas deferens present in normal conditions a high amount of mobile and mature sperm (millions) and may reach 100 times of the seminal sperm concentration (14-16) and therefore it is the ideal place to collect sperm, as already shown in a study of sperm collected in live individuals, before and after cryopreservation (16).

Due to the above considerations and the use of the described technique in this paper, when enough quantity of retrieved sperm is collected from the vas deferens ends, it is possible to dismiss the sperm retrieval of epididymis and/or testicles. In the present patient, three fragments of testicle were also harvested, due to the fact that the patient had a previous history of infertility and the sperm concentration at the fluid from vas deferens was low.

Regarding the time interval between death and sperm retrieval, it should be the shortest possible to obtain live spermatozoa with good motility, and it is suggested that it must not exceed 24 to 36 hours $(13,17)$. But there is a report of efficient sperm retrieval after 48 horas of death (12). In the present case, the elapsed time was almost 12 hours.

Regarding obstetric complications and/or congenital malformations, there are no reports in literature of increase due to the use of posthumous cryopreserved spermatozoa (18).

The quality of previous spermatogenesis is related to the presence of spermatozoa in the post mortem biological material. A study from Australia reported a failed sperm retrieval less than 24 hours after death of a patient with previous infertility (12). In the present patient, the spouse related that her husband was infertile, but the sperm analysis was performed elsewhere, that could not be accessed. The presence of previous husband infertility may explain the low quantity of retrieved sperm, but did not invalidate the employed described technique.

\section{CONCLUSIONS}

Sperm retrieval post mortem using bilateral in bloc ressection of testicle, epididymis and proximal part of vas deferens was efficient. It is suggested that these structures should be used, once they represent the physiological anatomic sites of spermatogenesis, sperm maturation and presence of mature spermatozoa.

\section{CONFLICT OF INTEREST}

None declared.

\section{REFERENCES}

1. Jones S, Gillett G. Posthumous reproduction: consent and its limitations. J Law Med. 2008;16:279-87.

2. Rothman CM. A method for obtaining viable sperm in the postmortem state. Fertil Steril. 1980;34:512.

3. Strong C, Gingrich JR, Kutteh WH. Ethics of postmortem sperm retrieval: ethics of sperm retrieval after death or persistent vegetative state. Hum Reprod. 2000;15:739-45.

4. Cavalcante MB, Duarte ABG, Araújo DO, Teles EPB: Criopreservação de sêmen humano - comparação entre métodos de congelação e tipos de envase. Rev. Bras. Ginecol. Obstet. 2006; 28:708-14.

5. Tremellen K, Savulescu J. A discussion supporting presumed consent for posthumous sperm procurement and conception. Reprod Biomed Online. 2015;30:6-13.

6. Pastuszak AW, Lai WS, Hsieh TC, Lipshultz LI. Posthumous sperm utilization in men presenting for sperm banking: an analysis of patient choice. Andrology. 2013;1:251-5.

7. Bahadur G. Death and conception. Hum Reprod. 2002;17:2769-75.

8. Landau R. Posthumous sperm retrieval for the purpose of later insemination or IVF in Israel: an ethical and psychosocial critique. Hum Reprod. 2004;19:1952-6. 
9. Ethics Committee of the American Society for Reproductive Medicine. Posthumous reproduction. Fertil Steril. 2004;82(Suppl 1):S260-2.

10. Coco BA. Reprodução assistida post mortem e seus aspectos sucessórios. JUS, 2012. Available at. <https://jus. com.br/artigos/21747/reproducao-assistida-post-morteme-seus-aspectos-sucessorios $>$.

11. Bruemmer JE. Collection and freezing of epididymal stallion sperm. Vet Clin North Am Equine Pract. 2006;22:677-82.

12. Jequier $A M$, Zhang M. Practical problems in the posthumous retrieval of sperm. Hum Reprod. 2014;29:2615-9.

13. Tash JA, Applegarth LD, Kerr SM, Fins JJ, Rosenwaks Z, Schlegel PN. Postmortem sperm retrieval: the effect of instituting guidelines. J Urol. 2003;170:1922-5.

14. Wen RQ, Li SQ, Wang CX, Wang QH, Li QK, Feng HM, et al. Analysis of spermatozoa from the proximal vas deferens of fertile men. Int J Androl. 1993;16:87-91.

15. Lorenzini F, Zanchet E, Lorenzini M. Sperm analysis of the vas deferens fluid after a long interval of unilateral percutaneous epididymal sperm aspiration in vasectomized patients. Int Braz J Urol. 2013;39:720-5; discussion 726.
16. Bachtell NE, Conaghan J, Turek PJ. The relative viability of human spermatozoa from the vas deferens, epididymis and testis before and after cryopreservation. Hum Reprod. 1999;14:3048-51.

17. Shefi S, Raviv G, Eisenberg ML, Weissenberg R, Jalalian L, Levron J, et al. Posthumous sperm retrieval: analysis of time interval to harvest sperm. Hum Reprod. 2006;21:2890-3.

18. Robson SJ, Campbell S, McDonald J, Tremellen K, Carlin E, Maybury G. Pregnancy and childhood health and developmental outcomes with the use of posthumous human sperm. Hum Reprod. 2015;30:2259-62.
Correspondence address: Fernando Lorenzini, MD, $\mathrm{PhD}$ Av. Sete de Setembro, $n^{\circ} .5 .388$ Curitiba, PR, 80240-000, Brasil E-mail: lorenzini.ff@gmail.com 